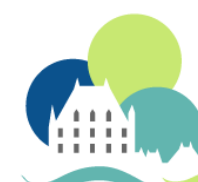

ISCAR 2017

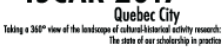

\title{
Effectiveness Analysis of the 12 Step Recovery Program from the Standpoint of the Cultural-historical Approach
}

\section{Marya S. Radionova}

RADIONOVA.M@LIST.RU

The Moscow Research and Practical Centre for Narcology

Moscow, Russia

\begin{abstract}
Some provisions of Vygotsky's concept allow us to understand in a new way the effectiveness of the action of 12 step programs in the recovery of addicts. From our point of view, the program implements the following provisions of the cultural-historical approach: the basis for human mental development is a qualiitative change in one's social situation; training leads to development; thanks to directive training, the addicted people aquire self-regulation; the program promotes the formation of the agency. Becoming a subject of one's own activity for getting rid of this dependency and its reflection, a person begins to change his/her life in many directions. The article analyzes the tools of the program, allowing to develop a agency position in the process of recovery: the content of the program, the community itself as a collective teacher, specific members of the community as role models of a healthy lifestyle.
\end{abstract}

Keywords : Cultural-historical approach; 12- step program; Community; Process of recovery of addicts; Developpement; Training; Agency position; Tools of the program. 
The cultural-historical approach of L. S.Vygotsky is traditionally applied to children's development. However, adult development is equally important and hinteresting. Different practices in the field of training, counselling, psychotherapy can be considered as practices of facilitating development (child or adult), and the theoretical basis for their analysis and organizations can serve as cultural-historical psychology (Kholmogorova \& Zaretskii, 2011).

In the focus of our attention are not just adults, but people who suffer from chemical addiction, and who have decided to break up with their addiction and try to recover by abandoning psychoactive substances. Recovery from chemical dependency is a long process that affects biological, psychological, social and spiritual spheres of a person's life. This is a process of recovery and development, the reverse of regression in all these spheres, which occurs as a result of the disease. Figuratively, this process can be represented as a gradual climb uphill after a period of descent and fall, as shown in the Jellinek curve (Glatt, 1958; Jellinek, 1952).

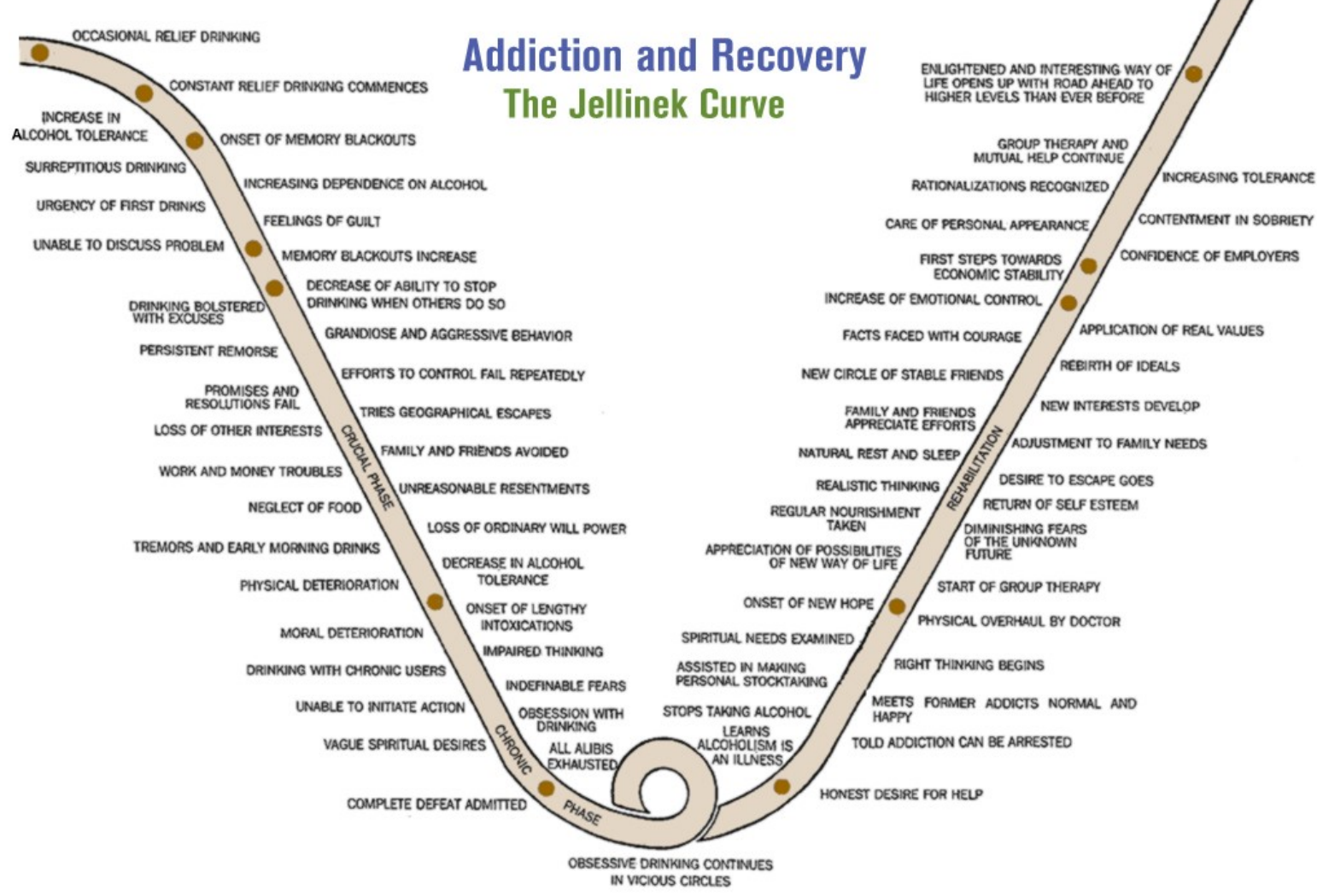

Figure 1. Addiction and Recovery. The Jellinek Curve

There is a telling parallelism between the symptoms of the disease and signs of recovery. As the disease develops, a person moves down the left curve, and the symptoms gradually increase. When he begins to recover (the right branch of the curve), these symptoms do 
not just change, but are replaced by their healthy opposite. In order for this to happen, continuous personal efforts of the patient are required. Conditions for the beginning of recovery, in addition to the rejection of a chemical substance, are: seeking help from specialists with further treatment and rehabilitation and / or self-help groups of the AN and the AA, working under the 12-step program.

According to the definition of M. M. Kabanov, rehabilitation involves the restoration of the patient's personal, social and legal status (Kabanov, 1998).

All addicts to alcohol and drugs have symptoms of personality disorder and impaired social functioning, either as a cause or as a consequence of drug use (de Leon, 1999). In addition, addicts often have premorbid traits of personal immaturity (Pyatnitskaya, 1994). Personality immaturity manifests itself in a lack of responsibility, an external locus of control, "inadequate self-esteem, disproportionate claims, weak self-control, impulsiveness, inadequate forecasts and reflection, immature defense mechanisms, unformed moral concepts" (Pyatnitskaya, 1994, p. 394).Therefore, simple recovery from the disease is not enough. In the event that the disease occurred in adolescence or early adolescence, often there is almost nothing to restore, since a person has not yet had time to build his personal foundation. In any case, alcoholism and drug addiction stop the development of personality - deform and destroy its value-semantic and motivational sphere, cognitive processes, their range of its interests is narrowed, social ties are violated. Years later, since the onset of the disease, the addict at best can only partially maintain its previous level and potential. During of treatment and rehabilitation, one must try to restore various spheres of his life. But a reliable result can only provide development (personal growth), which is associated with the formation of an agency position of the addict ${ }^{1}$. An object position occurs when the person is the object of rendering "medical care", "psychotherapeutic influence", where the responsibility for recovery lies with the doctor, therapist, or relatives more than the most dependent. Agency position means that a person recognizes his illness and assumes responsibility for his recovery, but realizes that he needs the help of others, that he alone cannot cope.

On the one hand, in this approach one can see a contradiction: agency is, as it were, "defective". On the other hand, it is necessary to take into account the specific nature of this disease, since the addict personality cannot help itself, because it is dominated by a dependent "I", living in illusions and distorted reality. Therefore, when a person recognizes that he is sick and needs the help of others, this is a manifestation of a healthy part of his "I". This agency position differs from the unproductive position "I myself" ( "I myself will stop drinking, using drugs, etc., when I will want"), inherent in the addict who

1. Agency (subjectness) - ability to independently create his own life, to make changes in oneself, and in a world that manifests itself in activity, communication and self-awareness (Stakhneva, 2010). The agency position - the position of the individual, which he can occupy in relation to various forms of activity (educational, professional, in communication with others, etc.). The agency position means an active and conscious attitude to the activity being carried out, and is considered as a resource and condition for maintaining and developing motivation for this activity (Zaretskii, 2014). The object position is manifested, when the individual primarily feels himself the receptor of external forces, demonstrating low activity and/or awareness. 
protects his addict identity by the negation of his disease. It can be said that the formation of a agency position in the treatment of this disease is a key moment and one of the most difficult tasks, given the typical for addict anozognosia.

State programs for the treatment and rehabilitation of chemically dependent create an opportunity for recovery, and sometimes for development, thanks to a common humanistic approach, principles of respect for human rights and dignity, the principles of informed and voluntary consent to treatment and rehabilitation (http://www.ecad.ru/standarty -reabilitacii-v-narkologii.html). However, with the medical model of rehabilitation, the agency position of the patient is not always supported. This model is a priori more authoritative, because it relies on the authority and responsibility of the doctor.

One of the most successful strategies for helping the addicts is a 12 Step program. However, serious studies devoted to the study of the effectiveness of the AA, AN are unfortunately not available (Brun \& Tsvetkov, 2014). This is due, inter alia, to the principle of anonymity, which hinders the conduct of scientific research, but not only with this. After more than 80 years of the existence of the 12-steps program debate over its effectiveness are still on the way. According to Sack, certified psychiatrist, narcologist, director of Elements of Behavioral Health, curator of several rehabilitation centers in Malibu and West Los Angeles, in Florida, Texas and New Mexico:

«There has always been a divide between two schools of thought on addiction: the scientific community and the recovery community. At least in part because of this divide, there is a lack of scientific evidence documenting how and why the 12-Step program works (though anecdotal evidence is abundant). Science has long dismissed 12-Step recovery, leaving a dearth of data where 75 years of history should provide much more, and 12-Step recovery has long rejected the need for and validity of scientific inquiry. But the necessary conclusion is not that 12-Step recovery doesn't work; rather, the research, to date, has been inadequate. It's unfortunate that 12 -Step recovery is widely misunderstood and underresearched. Even less fortunate is the fact that these misconceptions drive people away from the process before they can evaluate whether the program might make a difference in their recovery. Like any single approach to addiction, 12-Step recovery isn't for everyone. But for those who give it a fair try, the potential payoff is great. Recovery is not just about stopping one isolated behavior (drug use) but learning a new way of life - and this is the real value of 12-Step recovery».

Indirectly, the effectiveness of anonymous communities is evidenced by the constant increase in the number of groups in different countries. Today the number of groups working on this program in more than 200 countries of the world exceeds 100 thousand. The main task of the program is not only getting rid of alcohol or drugs, but changing the person's view of the world, a complete spiritual reorientation (Brun \& Tsvetkov, 2014). It is also included in many existing models of rehabilitation, for example, the Minnesota model. Although it was created without a reference to cultural and historical psychology, we tried to understand the conditions for the program effectiveness through the prism of Vygotsky's approach. From our point of view, the program implements the following principles of the cultural-historical approach: 
1. The basis for human mental development is a qualiitative change in one's social situation (Vygotsky, 2000). An addicted person, in accordance with the program, finds him self in a special social environment - a community that conforms to certain principles and traditions. The addict finds himself encircled by other people who used to suffer from similar addictions, and who can share their experience of overcoming it.

2. Training leads to development (Vygotsky, 1956). The entire program is built as a sequential training. For each step a whole system of tasks has been developed, which the addict manages on his/her own, if necessary turning to a sponsor who performs the functions of an assistant consultant. Thus, learning becomes a joint activity of two people, in which development is forming according to Vygotsky. Thanks to directive training, the addicted people aquire self-regulation. Thus, another principle of Vygotsky is realized.

3. The formation of an agency position as a process of mastering one's own behavior through incentives-means (Vygotsky, 1983). Becoming a subject of one's own activity for getting rid of this dependency and its reflection, a person begins to change his/her life in many directions.

4. Thus, one more thesis of Vygotsky is confirmed: "one step in teaching can give a hundred steps in development" (Vygotsky, 1982, p. 230).

\section{Discussion}

Personal lifestyles change in particular social environment. Negative views, attitudes and roles are not acquired in isolation, and cannot be changed in isolation (de Leon, 1999). Changing the social situation is vital for the addicts. All previous social connections and relationships are distorted by his illness and require revision, improvement or exclusion (for example, one's circle of joint consumers). To begin the process of positive changes, an addict needs a secure supporting environment. What can constitute such an environment? People who do not have addiction problems?- Perhaps, but among them the addict will most likely feel himself like "an alien", as the bearer of a shameful experience, which is usually to be concealed, and this will not contribute to its integration and profound personal changes. Professionals-psychologists? - Perhaps, but occasional meetings with just one specialist, cannot replace the social environment. An illuminating idea of the founders of AA has been to create a community of recovering alcoholics, and later drug addicts, etc.

AA communities served as a prototype of therapeutic communities (TS), a model that was subsequently used in many rehabilitation programs for chemically dependent people. The community in this model, in contrast to AA and AN, includes not only recovering addicts, but also consultants for chemical addiction (the addict on the long periods of sobriety that passed the program), physicians, psychologists, teachers and administration. In both cases of $\mathrm{AA}$ and $\mathrm{AN}$, the community acts as a supportive safe environment for building new healthy, open and honest relations. Other addict members of the group who 
have different periods of sobriety and different progression status within the program act to the beginners as a "mirror", reflecting the process of the changes that are coming to them, as well as the difficulties and problems that he will encounter along the way. This identification is important for the changes needed: it is easier to identify himself with another addict than with a healthy person. In the community, the recovering addict receives the social support he needs. The quality of this support, its availability and intensity are crucial. Using drugs, an addict can also receive social support from joint consumers, from co-dependent family members, which, nevertheless, aggravate his illness, and does not help get out of it. In contrast, social support in the communities of AA and AN stimulates the process of positive changes. This is because all members of the community are united by a common activity - recovery. Those who have advanced in this process share their experiences with the newcomers. The experience of others clearly shows that recovery is possible, that it is attractive and how it can be achieved. The availability of support is associated with the possibility of visiting groups. There are a number of principles of $\mathrm{AA}$ and $\mathrm{AN}$, among which is the recommendation "never to be too far from the place of assembly or from a person from the community to talk to" (Gorski, 2009). The intensity of support is related to the frequency of meetings' attendance and of the mentoring intensity. Typically, the newcomer is invited to attend 90 meetings in 90 days, which means daily conventions within the group. Afterwards, meetings frequency is gradually reduced to one or several times a week. Mentoring means finding a "sponsor", a person who will share his experience in completing the steps of the program, and who can communicate with him in any emotionally stressful situation. This helps to realize another principle of AA and AN, which is used when working on stress - described by the "HALT": the convalescents should not be too hungry (Angry), lonely (Lonely) and tired (Gorski, 2009). A qualitative change in the social situation is facilitated by the inclusion of close dependent people in the process of change when they begin to visit the Al-Anon and Nar-Anon groups organized for relatives. This does not exclude, of course, the help of professional family psychologists and psychotherapists.

What kind of training occurs during the passage of the "12 step" program? How does this affect development?

Briefly, and addict learns how to recover, how to fully and comfortably live in sobriety. As T. Gorski writes about this: "Recovery is the process of development. We go through a series of stages. This gradual effort to master new, increasingly complex skills. (...) All the skills needed to live long and sober directed to the search for meaning and purpose in life. Sobriety is a way of reflection, a path of action, a way of addressing other people. This is the philosophy of life. It requires daily efforts all over the course of the recovery program" (Gorski, 2009). Training takes place through mastering the experience of those who successfully recover from chemical dependence. Already from the time of creation AA in 1935, even before writing 12 steps (1938) and 12 traditions (1946), the transfer of experience occurred through personal communication - one alcoholic shares his vision of the problem with another. One of the founders of the AA community, Bill, wrote about this process: "First you have to show them their bottom, from a medical point of view, not regretting, tough (...).Tell them about the obsession that makes them drink, andtheir allergy, 
as a result of which they either go crazy or die if they continue to drink. Maybe, if these

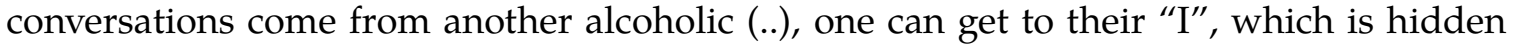
so deep. Then you can try another medicine - the ethical principles that you learned from the Oxford Group". Such was the advice given to Bill by his psychiatrist who treated him from alcoholism, gave to him after Bill, having obtained some spiritual experience, gave up alcohol. Over time, in AA, and then in other anonymous communities, the experience accumulated of thousands of recovering people allowed to generalize knowledge about the process of recovery, as well as "about dead ends and treacherous ravines", which can be avoided by using their instructions (Gorski, 2009).

The process of recovery (= development) includes several directions: setting real goals for personal growth at each stage of recovery, managing one's psychoemotional state, reassessing past life experience, correcting relationships with people, resolving current problems without psychoactive substances, the ability to receive and provide social support, development of empathy.

This is served: the content of the program, the community itself as a collective teacher, specific members of the community as role models of a healthy lifestyle.

The content of the program includes the philosophy of the program, steps and recommendations for their passage, a developed system of tasks and slogans.

The philosophy of the program is based on the evangelical life principles, while not being religious, because it does not formulate doctrine, rituals, and has no leaders. She invites to the organization of a person's life in accordance with his faith and open for those who consider themselves unbelievers or agnostics (Savina, 2015). The principle of anonymity is one of the fundamentals. In Fox's view (1993), the Anonymous Communities program is based on the religious philosophy of the Oxford groups. It emphasizes the importance of awareness of her own powerlessness, the need for self-analysis, confession, an analysis of their mistakes, redemption, appealing in prayer to the source of the Force outside of her own self. It also places emphasis on humility and the suppression of its Ego (Korolenko \& Dmitrieva, 2012). The importance of certain values for social learning and personal development is emphasized in the community. These values include: truth and honesty (in words and deeds), humility, trust, responsibility, personal responsiveness, concern for other members of the group (ministry and sponsorship), actions in place of illusions. The philosophy of the program is broadcast, including through short rules - slogans, which are clearly presented at meetings, and are also transmitted from person to person. The experience of many generations recovering from dependence is concluded in them.

Examples of slogans are: "First of all - the main thing!" (We are talking about recovery); "Live today, only today!"; "Live - and let's live another"; "Your head is a dangerous place, do not go there alone"; "We are claiming progress, not perfection"; "If you know everything - why are you here?".

Steps not only stop the dependence, but also guide the person along the path of selfknowledge, personal and social changes. For this, it is recommended that all 12 steps be 
carried out in sequence. Let us explain some steps. For example, the first step involves recognizing your powerlessness against a drug, your defeat, abandoning the hope for your " $I$ ", which is dependent ${ }^{2}$. The second step requires to answer the question what to do next, and what solutions others have found in solving this problem, by exploring he experience of those who could recover to sobriety and live a free productive life. The third step teaches that, even going by way of others, a recovering person will not necessarily receive exactly the same results. Therefore, he should strengthen the belief that "the Higher Power" can have special plans for him and accept what is happening with humility. This step allows us to realize our egocentrism, accept the limitations of our will and desires. The fourth step calls to look at one self honestly, without deceipt, acknowledging both own merits and shortcomings, realizing the reasons for what is happening to self. The addicts analyze grievances, feelings of guilt, fear, anger, the situations in which they are manifested, as well as "character defects". The fifth step can be compared with a confession. It removes isolation and guilt, allows you to find a realistic image of yourself. The eighth and ninth steps are concrete actions that allow patients to streamline their relations with others. They assume compensation for damage to those to whom it was inflicted during the period of substance use. The tenth step is continuation of introspection, and recognition of emerging errors, which means the need for daily attention to their actions and their motives.

The tasks developed for each step, in their content, are psychotherapeutic, aimed at increasing the level of self-reflection, reflecting situations, self-control, self-regulation, teaching the understanding and expression of emotions, tracking the manifestations of dependent thinking, and generally increasing the level of awareness. There are general recommendations of the program, for example, daily morning prayer, meditation, evening introspection, analysis of the day. Many dependent people who worked on the steps share the feeling that the program "sprouts", or, in the words of L. S. Vygotsky, it is internalized that the personality changes and this manifests itself in new ways of acting (Vygotsky, 2005, p. 344).

Community as a collective teacher. The community unites people who have a common problem, similar experiences, experience and a common goal - getting rid of addictions. It can say that the community is more than just the sum of individual members. How do they write Korolenko and Dmitrieva (2012): "At meetings of the society, emotions, intuition, "group thinking" and the influence of members of the community on each other are emphasized. During the meetings emerge a phenomenon of group consciousness, the exchange of experiences, personal stories". However, it is important to note that anonymous communities, despite having a certain anti-intellectual shade in their work, differ from cults, which was convincingly shown by Bufe (1991). At the beginning of the recovery path, regular participation in groups is the main guarantor of sobriety. This is the framework that keeps a person from "slide down" into dependence. This social environment, which protects him from loneliness, gives a sense of support and understanding. This is an

2. Powerlessness does not mean that the addict is inherently flawed, exempt from thinking for themselves or incapable of recovery, or that they can rely on their higher power to fix everything without taking steps to improve their own lives. That would contradict the entire premise of the 12-Step program. Instead, it is a statement about the nature of the disease, designed to remove the blame and shame that often prevent addicts from getting help, and to show addicts one way of reclaiming power over their lives (Sack, 2010) 
opportunity to learn new experiences of life, change beliefs and personality traits, which leads to the transformation of identity (Korolenko, Dmitrieva, 2012). When the program is mastered, the community becomes a way of bestowal, self-realization and service. Service is the practice of helping groups of AA and AN. In a broad sense, it is helping another person, expressing gratitude for own recovery. In a narrower sense, this is a way of gradually accustoming to take responsibility: buying and distributing tea and cookies, cleaning the room after the group, working with the literature of the community (Savina, 2015). 12 traditions are especially important for supporting the work of communities. Among these traditions is the priority of the general over the personal, the spiritual basis of the program, anonymity, the lack of authoritarianism, violence, exploitation, non-involvement in monetary relations, a certain autonomy from public.

Specific members of the community are models of a healthy lifestyle. For "beginners", it is, first of all, "old men" who can overcome dependence and realize themselves. A sponsor, which the "newcomer" chooses himself, is usually such a role model . The sponsor shares his experience of recovery without imitating the professional help of a psychologist (Savina, 2015, p. 598). This is a very important element of the program to maintain motivation for sobriety. The sponsor - this is not a "guru" and his words are recommendatory in nature. The communication with the sponsor can rightfully be called cooperation. It stimulates the development of the subjective position of the convalescent, the main characteristics of which are awareness and activity.

From all the above it follows that anonymous communities are built on the awakening and development of the agency position. Mastery of the program is possible only if you have your own activity and awareness. In the beginning, as is known, addict is characterized by externality, negation and avoidance. However, to come to the program and start participating in it, one must already show activity and an initial awareness of the existing dependence as a problem. In the future these two components of the subject position are maintained and developed through the working tools of the program. It should emphasize the importance of the following tools of the program: the introspection, the seeking help, the ministry, the steps, the visiting groups, the praying, the meditating, the communicating with the sponsor. For the development of the subjective position of the recovering, such principles of the program as honesty, openness for the new and readiness for action in place of illusions are also important. Such actions can be: a simple phone call in case of emotional instability, visiting groups, helping others, serving. In the process of passing the program, addicts take full responsibility for their recovery. The key position in the 12-step program is: "It's not our fault (and nobody else's) that we became addicted, but our responsibility is to recover". An even more difficult task for the addict, which can be solved during the passage of the program, is mastering one's own behavior.

Concerning Vygotsky's thesis: “one step in teaching can give a hundred steps in development", we see the 12th step of the program, which involves the application of program principles in all cases and the delivery of these ideas to other people, is particularly significant. 


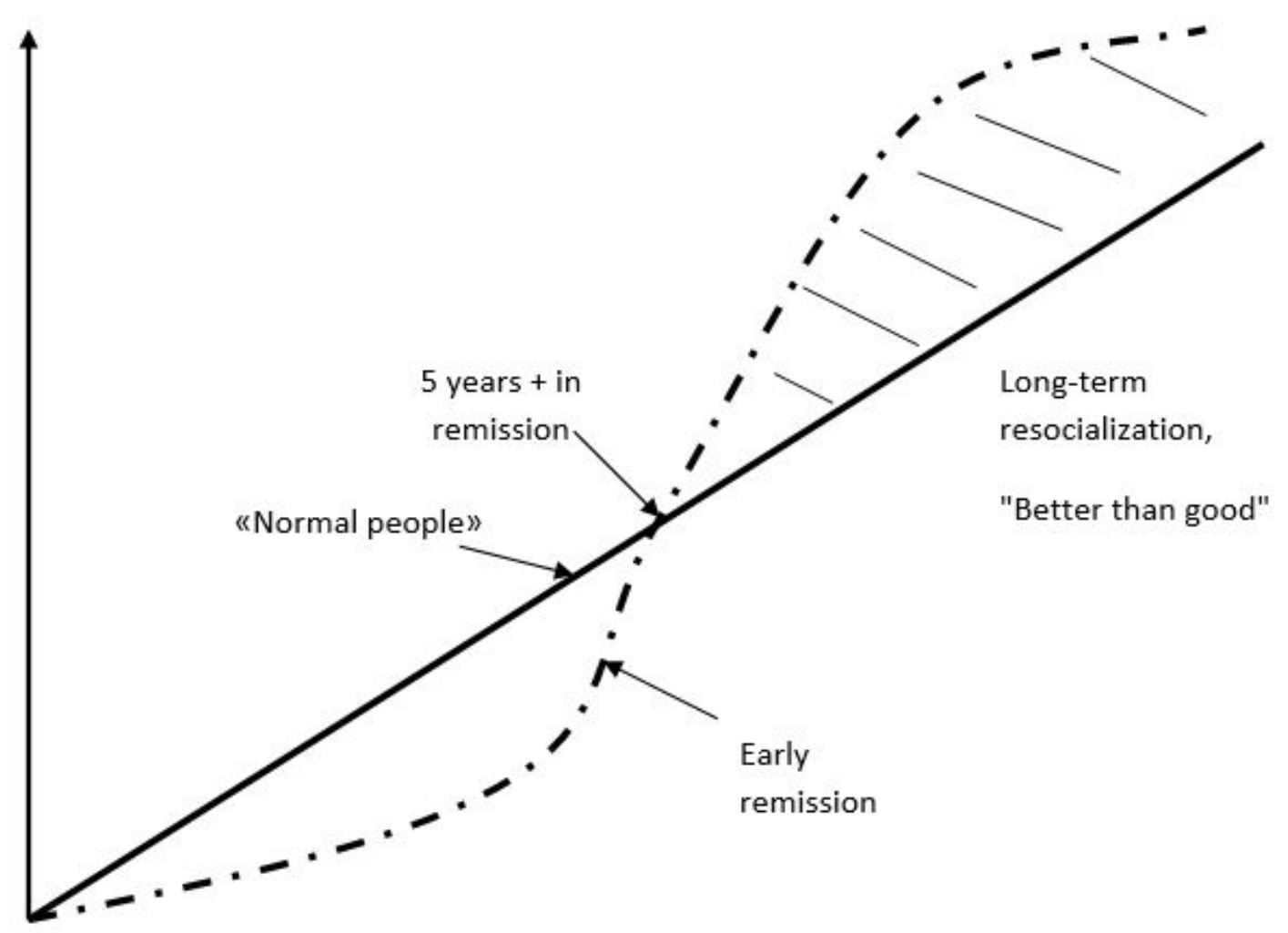

t, time

Figure 2. Change in personal potential of drug addicts when drug use is stopped.

With the course of remission, the personal potential of dependent people is sometimes more developed than that of "healthy people". This type of resocialization was called "better than just good" (de Leon, 2010). This phenomenon is associated with the hypercompensation of psychological and personal qualities dependent on drugs and alcohol, which go into a state of stable remission.

\section{Conclusion}

1. The scientific approach of L. S. Vygotsky allows one to answer questions about how and why the 12-step program works.

2. The main advantages of this program are: the creation of a qualitatively new social support environment; The focus on development and personal growth, which are provided by the reorientation of the value-semantic sphere and the training of skills necessary for long-term, sober life.

3. Stimulation and development of the subjective position of the convalescent manifests itself in the early stages of recognizing the illness and assuming responsibility for recovery, and further on in mastering one's own behavior. 
4. Changes in the life of addict, recovery-based 12 steps proceed according to several vectors of development: managing their psycho-emotional state, reassessing past life experience, correcting relationships with people, resolving current problems without psychoactive substances, the ability to receive and provide social support, the development of empathy.

5. The content of the program (program philosophy, steps, slogan rules), the community itself as a collective teacher, specific members of the community as role models of a healthy lifestyle and the bearers of the recovery experience, serve as the common tools for recovery.

6. Specific tools of the program that affect the development of the agency position are: self-analysis, appeals for help, ministry, work on steps, visiting groups, praying, meditating, communicating with the sponsor.

\section{References}

Brun, E. A., \& Tsvetkov, A. V. (2014). Practical psychology of dependence. Moscow: Nauka. Bufe, C. (1991). Alcoholics anonymous: cult or cure? San Francisco: Sharp Press.

de Leon, G. J. (1999). Therapeutic communities. In M. D. Galanter, D. Herbert, \& M. D. Kleber (Eds.), Textbook of substance abuse treatment. Washington, DC: The American Psychiatric Press.

de Leon, G. J. (2010). Is the therapeutic community an evidence-based treatment? what the evidence says. Therapeutic communities, 31(2), 104-128.

Glatt, M. M. (1958). Group therapy in alcoholism. Addiction, 54(2), 133-148.

Gorski, T. T. (2009). Passages through recovery: An action plan for preventing relapse. New York: Simon and Schuster.

Jellinek, E. M. (1952). Phases of alcohol addiction. Quarterly journal of studies on alcohol, 13(4), 673-684.

Kabanov, M. M. (1998). Rehabilitation of the mentally ill. Moscow: Meditsina.

Kholmogorova, A. B., \& Zaretskii, V. K. (2011). C mozhet li kul'turno-istoricheskaya kontseptsiya L. S. Vygotskogo pomoch' nam luchshe ponyat', chto my delaem kak psikhoterapevty [Can Vygotsky's cultural-historical concept help us to better understand what we do as therapists?]. Kul'turno-istoricheskaya psikhologiya [CulturalHistorical Psychology](1), 108-118.

Korolenko, T. P., \& Dmitrieva, N. V. (2012). Addiction: Handbook. Moscow: Institute for Counseling and System Solutions.

Pyatnitskaya, I. N. (1994). Narkomanii [Drug addictions]. Moscow: Meditsina Publ.

Sack, D. (2010). Why-the-hostility-toward-the-12-steps. https: //www . psychologytoday . com/ $\mathrm{blog} /$ where-science-meets-the-steps/201211/why-the-hostility-toward-the -12-steps.

Savina, E. A. (2015). Spiritual thirst: Recovery from alcoholism and drugs. Moscow: Meditsina Publ.

Stakhneva, L. A. (2010). Understanding the subject and subjectivity in modern psychology. scientific notes of orel state university. Moscow: Humanities and Social Sciences. 
Vygotsky, L. S. (1956). Problema obucheniya i umstvennogo razvitiya v shkol'nom vozraste [Issue of learning and mental development in school-aged children]. In Izbrannye psikhologicheskie issledovaniya [selected psychological works] (pp. 438-452). Moscow: APN RSFSR Publisher.

Vygotsky, L. S. (1982). Myshlenie i rech' [Thinking and speech], Vol. 2. Moscow: Pedagogika. Vygotsky, L. S. (1983). Collected works in 6 volumes. Vol. 3. Problems of psychic development. Moscow: Pedagogika.

Vygotsky, L. S. (2000). Problema vozrasta [The problem of age]. Moscow: Sobranie socinenij.

Vygotsky, L. S. (2005). Psihologiya razvitiya rebenka [Psychology of child development]. Moscow: Sobranie socinenij.

Zaretskii, Y. V. (2014). Sub'ektnaya pozitsiya shkol'nikov po otnosheniyu k uchebnoi deyatel'nosti $v$ raznykh vozrastnykh periodakh [Schoolchildren's position of agency towards the learning activity in different ages. Moscow: Ph.D. (Psychology) Thesis. 